\title{
The Role of Tele Dentistry During the Current Corona Virus Disease 2019 (COVID-19) And in The Possible Future Pandemic
}

\author{
Silvia Tortorici ${ }^{1}$ and Paolo Difalco ${ }^{2 *}$ \\ ${ }^{1}$ Professor of Oral Surgery. Department of Surgical, Oncological and Oral Sciences (Di.Chir.On.S.). University of Palermo; \\ Palermo, Italy
}

${ }^{2}$ Department of Surgical, Oncological and Oral Sciences (Di.Chir.On.S.). University of Palermo; Palermo, Italy

*Corresponding author: Paolo Difalco, Department of Surgical, Oncological and Oral Sciences (Di.Chir.On.S.). University of Palermo;

Palermo, Italy

\begin{tabular}{|c|c|}
\hline ARTICLE INFO & ABSTRACT \\
\hline Received: 慧 October 29, 2020 & Citation: Silvia Tortorici, Paolo Difalco. The Role of Tele Dentistry During the Current \\
\hline Published: 慧 November 02, 2020 & $\begin{array}{l}\text { Corona Virus Disease } 2019 \text { (COVID-19) And in The Possible Future Pandemic. Biomed J } \\
\text { Sci \& Tech Res 31(4)-2020. BJSTR. MS.ID.005124. }\end{array}$ \\
\hline
\end{tabular}

\section{Opinion}

Severe acute respiratory syndrome (SARS) coronavirus (SARS$\mathrm{CoV}$ ) is a virus that caused the first major pandemic of the third millennium [1]. SARS-CoV first emerged in 2002, before that, it was simply thought of as a benign virus, causing a common cold [1]. Fortunately, the medical and scientific community demonstrated marvellous efforts in the understanding and control of this first pandemic within a short time [2]. Seventeen years later, SARS-CoV-2 emerged for the first time. Actually, Corona Virus Disease 2019 (COVID-19) caused by SARS-CoV-2, is a pandemic that has affected more than 200 countries and it represents a really global emergency [3]. The SARS-CoV-2 is transmitted by inhalation or contact with infected droplets and the COVID-19 incubation period ranges from 2 to 14 days. Many people are asymptomatic, but anyone can have mild to severe symptoms. The most common symptoms are fever, cough, malaise and tiredness $[4,5]$. In addition, patients refer muscle aches, headache, loss of taste, loss of smell, sore throat, chest pain, congestion, runny nose, nausea, vomiting and diarrhea. According to CDC (USA Center for Diseas Control and Prevention) older adults and people who have severe underlying medical conditions like heart or lung disease or diabetes seem to be at higher risk for developing more serious complications from COVID-19 illness [5]. In fact, it may progress to pneumonia, acute respiratory distress syndrome (ARDS) and multi organ dysfunction. There are currently no specific treatments, cure, or vaccine for COVID-19. Several drugs and vaccine candidates are being studied in large clinical trials, but currently the only arms to combat COVID-19 are preventive hygiene measures such as social distancing, mask-wearing, quarantine and contact tracing. Although, it has been suggested that dentists must limit their practice only to emergencies, as restrictive measures to limit contagion, this is not always possible [6].

In fact, the main reasons to see a dentist are the pain or swelling in mouth, at face or at neck; in addition, there are other reasons such as orthodontic therapies or oral neoplastic lesions. In particular, oral cancer that must be identified in the early stages and treated immediately to avoid more serious outcomes, whilst orthodontic treatments require continuous monitoring by the orthodontist, who must evaluate the efficacy of the treatment. These treatments have need both regular and timely follow-up appointments [6]. This is where new technologies have come into play. A realistic and immediate solution, to limit the contact between dentists and patients, is the teledentistry. The term was first used by Cook in 1997, who defined teledentistry as the practice of using video- conferencing technologies to advice the treatment based on diagnosis over a distance [7]. The teledentistry can be used for preoperative assessment of an oral lesion, diagnostic purposes, or for consultation with another dental specialist. It can be particularly useful after the surgical excision of a lesion for postoperative wound assessment, from either a photograph of the surgical 
wound, via a health-monitoring machine, or an SMS from patients if they had an unusual symptom [8]. Teledentistry can be used tele-monitoring in place of conventional clinics follow-up, during orthodontic treatments. To reduce conventional clinics follow-up during orthodontic treatments, it is also possible carried out an orthodontic treatment based on dental aligners. These devices are realized with a digital technology that combined CAD (computer aided design) and CAM (computer aided design manufacturing) technology [9].

In summary, the orthodontist takes an impression of the patient's teeth, then he makes a dental model which is used to create a digital scan of the teeth. Using this teeth scan, a specific software suggests the steps or stages between the current and desired tooth position, in order to create aligners for each step of the orthodontic treatment. Then these virtual dental aligners are printed with a $3 \mathrm{~d}$ printer and patients can use the removable aligners that gradually straighten their teeth. Currently, the main role of teledentistry is only diagnostic, but in future other applications have also been involved oral surgery. According to Choi et al. telesurgery is an emerging surgical system that utilizes wireless networking and robotic technology to connect surgeons and patients who are distantly located from one another [10]. In the past the main limits of this robotic technology was the absence tactile sense. In fact, vision and tactile sense are the principal sensory inputs employed by humans in object manipulation tasks [11]. Using haptic technology, an oral surgeon will be able to realize a surgical treatment. The word "haptics" comes from the greek words haptikos (meaning able to come into contact with) and haptesthai (meaning touch or contact). Haptic technology is currently used in robot -assisted telesurgery. The haptic interface is a device that allows a virtual or remote environment to stimulate the sense of touch on a human operator. Today, a number of haptic interfaces with different structures have been developed, and are commercially available. These devices have been widely used in a multitude of applications such as graphical user interfaces, games, education and training etc [11].

\section{ISSN: 2574-1241}

DOI: $10.26717 /$ BJSTR.2020.31.005124

Paolo Difalco. Biomed J Sci \& Tech Res

This work is licensed under Creative Commons Attribution 4.0 License

Submission Link: https://biomedres.us/submit-manuscript.php
Using haptic interfaces it will be possible, also, to carry out an oral surgical procedure in telesurgery. The idea to use telesugery is not science fiction, but has become reality. It is our opinion that the development of this technologies, will allow perform complex oral surgical procedures with more accuracy, speed, and safety. The safety of teledentistry is the physical distance between dentist and patients. In the future, if we will have new pandemic, physical distance will play a crucial part in helping to prevent the spread of these virus, thus the development of teledentistry, telesurgery or telemedicine must be a priority.

\section{References}

1. Cheng VC, Lau SK, Woo PC, Yuen KY (2007) Severe acute respiratory syndrome coronavirus as an agent of emerging and reemerging infection. Clin Microbiol Rev 20: 660-694.

2. Park S, Hahm DH, Joo M, Kim K, Kwon S, et al. (2020) The role of Korean Medicine in the post-COVID-19 era: an online panel discussion part 2 basic research and education. Integr Med Res9: 100488.

3. WHO? Coronavirus disease 2019 (COVID-19). Situation Report - 94.

4. Chakraborty I, Maity P (2020) COVID-19 outbreak: Migration, effects on society, global environment and prevention. Sci Total Environ 728 : 138882 .

5. (2020) Center for Diseas Control and Prevention (CDC). Coronavirus Disease (COVID-19.

6. Maspero C, Abate A, Cavagnetto D, El Morsi M, Fama A, et al. (2020) Available Technologies, Applications and Benefits of Teleorthodontics. A Literature Review and Possible Applications during the COVID-19 Pandemic. J Clin Med 9(6): 1891.

7. Karthikayan R, Sukumaran A, Diwakar MP, Raj V B (2019) Accuracy of smartphone-based photography in screening for potentially malignant lesions among a rural population in Tamil Nadu: A cross-sectional study. Digit Med 5(2): 56-61.

8. Asiri A, AlBishi S, AlMadani W, ElMetwally A, Househ M, et al. (2018) The Use of Telemedicine in Surgical Care: A Systematic Review. Acta Inform Med 26: 201-206.

9. Malik OH, McMullin A, Waring DT (2013) Invisible orthodontics part 1: invisalign. Dent Update.; 40: 203-215.

10. Choi PJ, Oskouian RJ (2018) Tubbs RS Telesurgery: Past, Present, and Future. Cureus. 10(5): e2716.

11. Tortorici S, Difalco P (2019) Current and future use of virtual and augmented reality in minimal invasive oral surgery. J Transl Sci 6: 1-2.

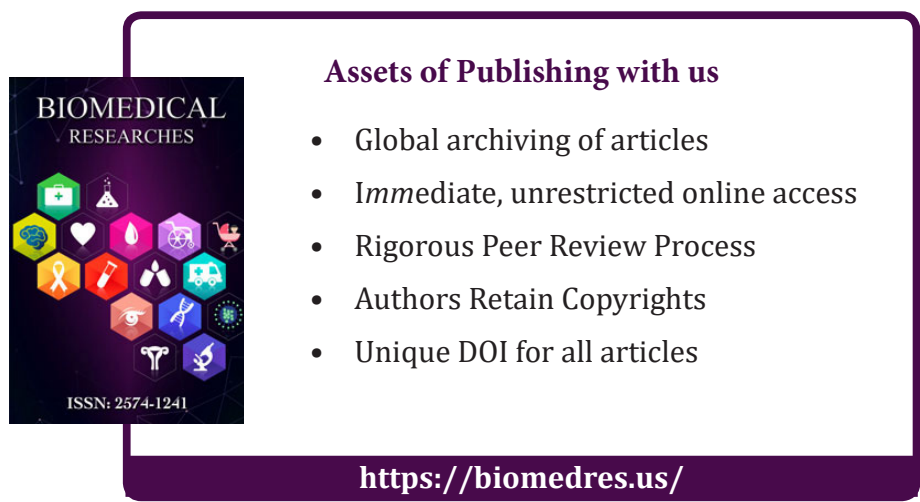

